\title{
Glossário -construção inter e transdisciplinar de saberes assente na prática colaborativa
}

Anabela Lima Maria

Escola Pedro Ferreiro

\begin{abstract}
Resumo
A reflexão sobre a educação para o século XXI continua a ser alvo de preocupações, face aos apelos da nova era. Considerar, por um lado, a língua e as competências comunicativas como fulcrais para a construção do conhecimento, é essencial no contexto educativo; por outro, envolver os estudantes nessa construção é torna-se imperioso. Daí que nos proponhamos abordar a pertinência de uma conceptualização rigorosa, como forma de sustentar e consolidar o conhecimento, em particular, a construção de glossários, nas diferentes áreas implicadas nos cursos/unidades curriculares de licenciatura do ensino universitário particular, em Moçambique, enfatizando as dimensões inter e transdisciplinar.

Palavras-chave: construtivismo social; aprendizagem colaborativa; glossário.
\end{abstract}

\section{Século XXI: Uma Sociedade em Mutação}

A reflexão sobre uma educação adaptada ao século XXI foi alvo de preocupações desde os anos setenta, com os relatórios da Comissão Europeia, com autores como Carneiro $(2001,2011)$ e outros como Gadotti (2000) que aborda a questão da perplexidade com que os educadores se confrontaram, face aos apelos da nova era. Roberto Carneiro defende, num artigo publicado em 2013, que, dar sentido à vida e à aprendizagem é fundamental e, na verdade, a procura do sentido da vida faz parte da condição humana. O mesmo autor (op.cit., p.1) refere, no entanto, que:

We live in a special age, contrary to meaning- making:

That of the death of distance and time, enslavement to the urgent, information over load, inconsequent activism, materialist drive that turns consumption into the mother of all ambitions, decline of the basic structures of socialization namely family and school, functionalization of the education system, limitless competition, celebration of eternal youth, publicity illusion.

Estamos, pois, a viver uma era de mudança em que os valores tradicionais foram colocados em causa, já que, muitos tinham a crença de que o crescimento económico seria consistente, que a globalização traria apenas aspectos positivos e que a vasta informação, ao dispor das pessoas, poderia suplantar o conhecimento e a aprendizagem.

Esta visão da sociedade ocidental leva-nos a reflectir sobre a pertinência dos relatórios Aprender a Ser (Faure, 1972) e Educação Um Tesouro a Descobrir (Delors, 1996). Os dois eixos cruciais apontados por Faure (op. cit.) são a importância da educação permanente e a ideia da 'cidade educativa', destacando a necessidade de proporcionar a todos o acesso à educação. Esta que surge, pois, com um carácter universal, focada no homem, enquanto elemento de uma comunidade, devendo ela proporcionar o potenciar e o aperfeiçoamento das qualidades humanas. É, então, o reforçar da ideia de uma educação holística e humanista. Nesta linha, também Delors (op. cit.), refere a educação como crucial para a construção da paz mundial e, portanto, de um mundo mais justo, alertando para a importância da convivência 'na aldeia global', assim como, nas comunidades em que cada um se insere. Esta é, com efeito, uma das nossas preocupações: a importância de estabelecer interconexões entre a pertença a uma comunidade e, ao mesmo tempo, aprender a agir sobre ela. É através da educação que poderemos ultrapassar as dificuldades do mundo contemporâneo, identificadas por Carneiro (2013), e às quais anteriormente aludimos.

Alertamos para o facto de que as características da 'nova sociedade' fizeram acreditar que o desenvolvimento económico seria permanente, que a humanidade poderia evoluir com os novos valores do individualismo, do consumismo, do facilitismo, do conformismo. No contexto deste debate, os autores divergem quanto às consequências das vivências sociais deste milénio. Assim, trazemos a discussão, por um lado Estevão (2009), que considera a realidade da competitividade global um factor positivo para os mais desfavorecidos, podendo mesmo "atenuar a pobreza global”; por outro lado, Tedesco (2003) apresenta as mudanças recentes como um factor de desigualdade social o que, segundo entendemos, se estende a nível dos diferentes países com consequências sobre as pessoas.

Mia Couto (2012), na sua aula inaugural na Faculdade de Artes e Comunicação, da Universidade Eduardo Mondlane, em Maputo, aborda esta problemática, apresentando-a como um paradoxo, ou seja, deixa a ideia de que, se a função de todos os cidadãos é produzir riqueza, não faz qualquer sentido que se vejam acentuadas as desigualdades sociais. Ao mesmo tempo, indica que a exaustão e a pobreza interiores, bem como a falta de esperança, levam as pessoas a banalizarem a sua própria vida.

Nesta apresentação são elencados dilemas importantes, que nos levam a afirmar a centralidade a ser dada a uma formação integral e continuada. Na maior parte das sociedades, hoje em dia, é aceite que ter um emprego fixo já não é apanágio deste século; por isso, as organizações com responsabilidade em matéria de educação falam da formação para a empregabilidade, mas diremos nós, ela deverá também apelar para o usufruto dos bens culturais e ambientais que estão ao dispor do homem.

\section{Mudança de Paradigma: a sociedade da aprendizagem}

Tal com já referimos, a educação é central na mudança, mas o próprio mundo educativo encontra-se numa encruzilhada entre o tradicional e o actual. Esta ideia é claramente apresentada por Carneiro (2013:3) ao afirmar que: "Education, an eminently social function, is caught 
in the crossfire of two different types of society. Located on the fine line dividing permanence and change, conservation and innovation, the function of education is under unprecedented stress"; contudo, o autor esclarece que: “(...) upon education lie all hopes of bettering future societies. In the age of knowledge and information, education reacquires a most prominent position in building vision for the collective future".

Desta forma, e reconhecendo que é forte a interação entre a escola e a sociedade, cremos que a chave do progresso humano está na educação dos cidadãos, por forma a tornarem-se mais conscientes dos seus direitos, dos seus deveres sociais e, consequentemente a sentirem-se mais seguros, face à evolução acelerada do mundo em que estão inseridos. Daí que, é nossa conviç̧ão que as instituições educativas devam ver o momento de transformações como uma oportunidade para se (re)estruturarem, para implementarem práticas inovadoras, nomeadamente procurando aproximações inter e transdisciplinares. Desde o final do século XX que o mundo da educação tem vindo a reflectir sobre a mudança de paradigma, transpondo o eixo do ensino para o da aprendizagem, dando relevo, em particular, a duas dimensões que consideramos fulcrais: por um lado, o centramento do processo no aprendente, devendo este, assumir a responsabilidade pela sua formação, estando alerta para a importância de o fazer de forma continuada e ao longo do ciclo vital, e por outro, o reforço da concepção holística da aprendizagem, ou seja, a formação dos cidadãos no plano da complexidade.

Tal como apresenta Morin (2002:42):

O conhecimento pertinente deve afrontar a complexidade. Complexus significa o que é tecido em conjunto; (...) existe complexidade desde que sejam inseparáveis os elementos diferentes constituindo um todo (...) e desde que exista tecido interdependente, interactivo e inter-retroactivo entre o objecto de conhecimento e o seu contexto, as partes e o todo, o todo e as partes, as partes entre elas.

$\mathrm{O}$ autor, entre as diversas vertentes da vida do ser humano que reconhece como um 'todo', aponta a económica, a política, a sociológica, a psicológica, a afectiva e a mitológica; entende também que existe uma ligação entre a ‘unidade e a multiplicidade' que, na nossa perspectiva, se gera nesse inter-relacionamento entre o sujeito e o mundo que o envolve. Por isso, reconhecemos a falta de sentido num conhecimento espartilhado e uniforme que mostra tendência para limitar o desenvolvimento integral do ser humano.

Essa é a razão, pela qual importa procurar uma visão de conjunto dos diversos saberes, de modo a estabelecer pontes interdisciplinares entre as diversas ciências e ainda a integração de aprendizagens do âmbito do exercício da cidadania.

As mudanças têm sido muito lentas e, pelo menos desde o princípio do novo milénio, que tem estado em aberto o caminho para o novo paradigma educacional, não tanto a nível das políticas educativas, mas em alguns nichos de investigação educativa. Deste modo, o dilema da mudança continua no centro da discussão, faltando, de acordo com o nosso ponto de vista, 'dar o salto qualitativo’ para o futuro.

\section{O Glossário: um recurso de desenvolvimento da aprendizagem}

Certa de que as instituições de ensino quer de nível secundário, quer de nível superior, devem dar resposta aos reptos colocados, centrando o processo educativo na aprendizagem, importa realçar, como elemento facilitador dessa mudança de atitude, o papel da(s) língua(s) e das novas tecnologias como suporte à dinâmica comunicacional que sustenta e dinamiza o processo de ensino e aprendizagem. Propomo-nos, pois reflectir sobre este papel facilitador no âmbito do curso de Ciências de Educação de uma instituição do ensino privado em Moçambique - a Universidade Metodista Unida [UMUM]. Este curso tem como finalidade dotar os estudantes de ferramentas técnico-científicas que, numa perspectiva conceptual e prática, contribuam para a sua formação, enquanto educadores na sociedade contemporânea, impulsionando a investigação e a reflexão centrada na educação, nomeadamente nas diferentes áreas científicas que a sustentam. Destacamos em particular o contributo das correntes contemporâneas de educação, tendo em vista uma dinâmica de investigação, reflexão e aç̧ão, enfatizando, assim, a componente teórico-prática da investigação educativa, pondo em destaque uma formação integral do ser na interacção e articulação com o(s) outro(s).

Por um lado, as tecnologias, a língua e as competências comunicativas são centrais, para a construção do conhecimento e essenciais no contexto educativo; por outro, implicar os estudantes nessa tarefa cognitiva é imperioso. Valorizamos, em particular o seu envolvimento no aprofundamento do conhecimento, não os reduzindo a meros receptores; por isso, cremos que a implementação de metodologias activas, por parte dos docentes, se impõe. Deste ponto de vista, o professor surge como um orientador, provocando a aprendizagem e consequentemente proporcionando a apropriação do conhecimento por parte dos discentes.

Ao colocar o aprendente como principal actor do processo de ensino e aprendizagem, pretendemos, tal como anteriormente referimos, valorizar as dimensões de investigação e reflexão, acompanhadas de processos de regulação, no sentido de incentivar a metacognição e a meta-avaliação; defendemos, pois a importância da reflexão sobre a aprendizagem e sobre o processo desenvolvido para chegar ao conhecimento, induzindo-os ao questionamento, à descoberta, promovendo em simultâneo o espírito crítico, a autonomia, a responsabilidade. Evidenciamos, que importa que cada aprendente seja valorizado na sua dimensão holística, e que possa enriquecer a comunidade de aprendizagem, tendo por base o trabalho colaborativo, com os seus conhecimentos anteriores e com a sua experiência de vida, funcionando isto, como ponto de partida para as novas aprendizagens.

Ao concebermos o professor como um organizador de aprendizagens, fazemo-lo no pressuposto de que a actividade docente não é um acto isolado, antes, um processo cooperativo e colaborativo, privilegiando as aprendizagens inter e transdisciplinares. Nesta reflexão que agora apresentamos, destacamos a pertinência de 
uma conceptualização rigorosa, como forma de sustentar e consolidar as aprendizagens, em particular, pela construção de glossários, nas unidades curriculares [UC] das diferentes áreas estruturantes dos diversos cursos de licenciatura da UMUM.

\section{O recurso à inter e à transdisciplinaridade no curso de Ciências da Educação}

As referências de Delors (1996) ao conceito de sociedade educativa levam-nos a pensar na possibilidade que todos temos em potenciar sinergias na interacção com os outros. A sociedade educativa é uma consequência da sociedade da aprendizagem, na qual, aprender se traduz num 'dever moral', em lugar de uma ideia que ainda persiste do aprender como 'direito'. Assim, o projecto em fase de implementação, na UMUM, preconiza potenciar a criação de comunidades de aprendizagem que envolvam_estudantes e docentes das diversas UC, de forma a promover o a implicação num projecto comum, conducente ao enriquecimento pessoal e profissional de todos os envolvidos. Desta maneira, ao ser concebido o curso de Ciências da Educação é clarificado o propósito de acompanhar os desafios do século em que vivemos. Procuramos enfatizar os quatro pilares da educação postos em destaque no Relatório Delors, supra referido, e pensamos no seu alargamento a outros saberes: o saber (com)viver e o saber agir, atendendo às demandas do século do tempo presente e do futuro. Se entendermos que a noção de interdisciplinaridade entra no mundo da educação de modo a que alguns conteúdos, conceitos e temas possam ser abordados de forma articulada e complementar por diversas áreas disciplinares, então podemos destacar a determinação de implementar o trabalho colaborativo e cooperativo de modo a contribuir para aprendizagens mais consolidadas.

Vemos, portanto, o desenvolvimento das diversas UC que integram o plano da licenciatura e mestrado, num trabalho partilhado em (co)operação e (co)laboração, numa dinâmica centrada nas aprendizagens de e entre estudantes e docentes, gerando assim o reforço do que anteriormente abordámos: uma comunidade de aprendizagem em que os intervenientes se sintam implicados e envolvidos.

Neste processo de repensar o futuro, trazemos a debate autores como Vigotsky, Dewey e Nicolescu, sobretudo no que concerne a perspetivas do construtivismo social, das metodologias ativas e da transdisciplinaridade, respectivamente, na medida em que os saberes estão cada vez mais interligados, criando redes de complexidade que, requerem um envolvimento crescente dos indivíduos. Ao mesmo tempo, a partilha e a colaboração são também competências que, uma vez desenvolvidas, facilitam a aprendizagem e contribuem para a autonomia. Enfatizamos o contributo de Vigotsky, pela sua proposta de construtivismo social e pela valorização tanto do contexto cultural, como da linguagem para o processo de aprendizagem. No pensamento deste autor está, pois, plasmada uma grande abrangência no que concerne à importância do meio e à sociabilidade; é também destacado o relevo que dá à cultura, à história e à linguagem como elementos catalizadores para a apropriação do(s) conhecimento(s) específicos dos diferentes domínios que integram a área das Ciências da Educação ou que com ela se articulam.

Realçamos ainda o pensamento de Nicolescu (1997:§6) ao conceptualizar a noção de transdisciplinar, "Como o prefixo "trans" indica, a transdisciplinaridade diz respeito ao que está, ao mesmo tempo, entre as disciplinas, através das diferentes disciplinas e além de todas as disciplinas. Seu objetivo é a compreensão do mundo presente, e um dos imperativos para isso é a unidade do conhecimento.” Assim, transdisciplinar é o que está 'entre', 'através', e 'para além’ das disciplinas, sendo dado destaque às competências transversais, estas, essenciais a aprendizagens diversificadas e consolidadas e também à integração pessoal e social.

Assinalamos, que o desenvolvimento das TIC contribuiu para a globalização da informação, o que aceitamos como um factor positivo do novo milénio, pois reconhecemos que, se bem geridas, as TIC nos permitem, pela primeira vez na história da humanidade, partilhar informações, conhecimentos e aprendizagens, ao mesmo tempo, em espaços distintos, sem nos darmos conta nem dos lapsos temporais, nem das distâncias físicas que nos separam. No entanto, esta mais-valia pode, se não bem utilizada, transformar-se em mais um factor de desigualdade, aumentando o fosso entre os que 'sabem' e os que ‘não sabem'.

Assim, faz todo o sentido que as TIC integrem as competências transversais a desenvolver, em particular, no e pelo uso de plataformas digitais, instrumentos facilitadores, tanto da aprendizagem como da comunicação, pois, em acordo com Dias (2013:5), a rede transforma-se num espaço aberto de partilha e de interacções, de extrema importância no contexto educacional:

A globalização das práticas de comunicação e experiência do conhecimento na sociedade digital promove a construção de novas proximidades sociais e cognitivas nos processos de educação, para os quais a distância deixa de constituir um limite no acesso à educação e à aprendizagem. A rede é o espaço para as interações, a partilha de conteúdos e representações, e o meio para o acesso à educação e aos contextos de aprendizagem.

\section{A construção do Glossário de Ciências da Educação}

Ciente de que o facto de termos mais informação disponível não é sinónimo de melhor conhecimento ou melhor aprendizagem, ponderamos a construção do glossário - neste caso, a nível do curso de Ciências da Educação da UMUM, como um instrumento de cariz científico, rigoroso, mas flexível e em constante aperfeiçoamento. Em termos denotativos, em sentido literal, 'glossário' é uma listagem de termos técnicos,-relacionados com uma determinada ciência ou arte, pelo que de acordo com as diversas ciências e áreas do conhecimento, podem surgir glossários específicos.

Sendo a área em que nos movemos a das Ciências da Educação, perspectivamos este trabalho nesta área científica e entendemo-lo - o glossário - como um instrumento de trabalho em processo e progresso, atendendo à evolução constante dos saberes, portanto, com um dinamismo próprio; não o vemos como algo 
encerrado ou cristalizado, mas antes como meio para a construção/compreensão da linguagem científica, nomeadamente das terminologias específicas, já que aceitamos que cada área científica reúne termos e conceitos próprios a ela atinentes. Todavia, preconizamos, neste projecto uma abrangência a diversas áreas do saber, constituindo-se assim, a construção de glossários como uma oportunidade de trabalho entre pares ou em grupos que, pela sua natureza, potencie a comunicação e a interação - o trabalho colaborativo -, rentabilizando a aprendizagem e contribuindo para discussão e consolidação dos(s) conhecimento(s) em questão.

A oportunidade de construção do(s) glossário(s) surge, então ${ }_{2}$ do facto de se ter instituído a língua portuguesa, a língua inglesa e as novas tecnologias como UC transversais, no primeiro ano dos cursos de graduação. Este trabalho centra-se, portanto, na problematização da pertinência e utilidade dos glossários das diferentes áreas que estruturam os cursos da UMUM.

Cremos ainda que, se por um lado, importa reconhecer o valor das competências comunicacionais, no sentido de tornar este instrumento uma ferramenta de trabalho, por outro, pensamos que um glossário de termos específicos das áreas das Ciências da Educação pode também contribuir para a interdisciplinaridade, uma vez que implica o envolvimento de várias UC do curso e ainda porque conduz ao entrecruzar dos conteúdos dessas mesmas UC. Como já referimos, sendo a língua portuguesa a língua oficial - a UC Técnicas de Expressão Oral e Escrita [TEOE], transversal a todos os cursos, funciona como suporte a todo este processo de construção, na medida em que viabiliza uma comunicação mais eficaz. Da mesma forma, a UC Inglês, por ser a língua franca, valoriza ainda mais este trabalho, já que, sendo o glossário bilingue, estimula e favorece a investigação e permite mais facilmente a aproximação aos vários países dos PALOP, contribuindo, assim, para tornar conhecida a UMUM, na região, no país, e em simultâneo, para a sua internacionalização, ao mesmo tempo que facilita a assunção do status de cidadão do mundo.

A UC TIC, para além de responder a um dos reptos da educação do nosso tempo, permite o esbater das distâncias, criando novos tempos e novos espaços de aprendizagem, reduzindo assim as desigualdades no acesso e na produção do conhecimento. É por isso, também uma UC transversal que serve de suporte à concepção digitalizada e organização informatizada dos glossários. Destacamos ainda que é uma UC que, pelas suas especificidades, permite o recurso a instrumentos facilitadores da construção e da partilha do conhecimento.

Uma outra UC transversal, a da Metodologia Científica, que integra os dois semestres do segundo ano, ao iniciar os alunos nas metodologias de investigação, consolida e renova os conteúdos do glossário iniciado no primeiro ano das licenciaturas.

\section{Considerações conclusivas}

A finalizar, lembramos que, do ponto de vista de Vigotsky a língua se constitui como o elemento primordial de mediação entre o aprendente, que, na interacção social se apropria do conhecimento, e que o vai aprofundando e consolidando. A construção do glossário é um exemplo desta dinâmica, uma vez que exige, por parte dos intervenientes, uma reflexão pela e sobre a língua, não apenas como instrumento de comunicação e disseminação, mas também de afirmação pessoal e, neste caso, de uma comunidade aprendente agentes de educação, na sua dupla dimensão: professores e estudantes; aprendentes e aprendizes. Esta dinâmica de aprendizagem poderá ser um nicho de desenvolvimento académico e de formação humana que consubstancie as transformações, em linha com o novo paradigma educacional do século XXI no que à sociedade de aprendizagem diz respeito.

Nota: A autora não segue o novo acordo ortográfico.

\section{Referências}

Carneiro, R. (2001). Fundamentos da Educação e da Aprendizagem, 21 Ensaios para o Século 21. Vila Nova de Gaia: Fundação Manuel Leão.

Carneiro, R. (2011). Discovering the Treasure of Learning. In Conceptual Evolution and Policy Developments in Lifelong Learning. Hamburgo: UNESCO, Institute for Lifelong Learning.

Carneiro, R. (2013). Leaving by Learning, Learning by Leaving: The Quest for Meanig. International Review of Education. doi:10.1007/s11159-013-9355-3

Delors, J. (1996). A Educação, um Tesouro a Descobrir. Porto: Edições ASA.

Dias, P. (2013). Inovação pedagógica para a sustentabilidade da educação aberta e em rede. Educação,Formação\&Tecnologias, 6 (2), pp. 4-14. Obtido de http://eft.educom.pt

Estevão, C. V. (2009). Cosmopoliticity and Adult Education in the Era of Globalization. In Educação em Revista, v. 10, n. ${ }^{\circ}$ 1, pp. 101-112.

Faure, E. (1973). Aprender a Ser, La Educación del Futuro. Madrid: Alianza Editorial.

Gadotti, M. (2000). Perspectivas actuais de Educação. Perspectivas, 14 (2), 1 pp. 03-11. doi:10.1590/s0102-88392000000200002

Morin, E. (2002). Os Sete Saberes para a Educação do Futuro. Lisboa: Instituto Piaget.

Nicolescu, B. (1997). A Evolução Transdisciplinar, na Universidade - Condição para o Desenvolviemnto Sustentável. In Congresso Internacional A Responsablidade da Universidade para com a Sociedade. Bangkok: Chulalongkorn University. Obtido em 25 de Maio de 2011, de http://basarab.nicolescu.perso.sfr.fr/ciret/bulletin/b12/ b12c8por.htm\#note

Tedesco, J. C. (2003). Los Pilares de la Educación del Futuro. In Debates de Educación. Obtido de http://www.uoc.edu/dt/20367/ 